\title{
Uso de regressão e redes neurais artificiais na estimativa do volume de Khaya ivorensis
}

\author{
Lucas Sérgio Sousa Lopes ${ }^{1 \star}$, Rafael Rode ${ }^{2}$, Daniela Pauletto², Diego Damázio Baloneque ${ }^{2}$, Fábio Guerra \\ dos Santos ${ }^{3}$, Arystides Resende Silva ${ }^{4}$, Daniel Henrique Breda Binoti ${ }^{5}$, Helio Garcia Leite ${ }^{1}$ \\ ${ }^{1}$ Universidade Federal de Viçosa, Viçosa, Minas Gerais, Brasil. \\ ${ }^{2}$ Universidade Federal do Oeste do Pará, Santarém, Pará, Brasil. \\ ${ }^{3}$ Instituto Brasileiro do Meio Ambiente e dos Recursos Naturais Renováveis (IBAMA), Brasília, Distrito Federal, Brasil. \\ ${ }^{4}$ Embrapa Amazônia Oriental, Belém, Pará, Brasil. \\ ${ }^{5}$ DAP Engenharia Florestal, Viçosa, Minas Gerais, Brasil.
}

\begin{abstract}
RESUMO Este trabalho objetivou comparar o volume de árvores de mogno africano estimado pelo modelo de Schumacher e Hall e por redes neurais artificiais. A coleta de dados ocorreu em dois sistemas agroflorestais no município de Belterra, Pará, com 7 e 11 anos de idade. Em cada local foram cubadas 34 árvores em pé. Para as estimativas de volume comercial foram empregadas as formas do modelo de Schumacher e Hall (linear e não linear) e uso de redes neurais artificiais (RNA) do tipo Multilayers perceptron. As arquiteturas de RNA com 4 neurônios na camada de entrada propiciaram as melhores estimativas e valores de erro, sensivelmente melhores do que os modelos volumétricos, tendo as RNA um erro 36,7\% menor que o modelo de Schumacher e Hall não linear. Este último modelo apresentou tendência a superestimar os volumes e a RNA obteve estimativas mais livres de tendências. As redes neurais artificiais geraram estimativas com maior precisão em relação às formas do modelo de regressão. Essa técnica mostrou-se viável, pois uma única rede pode estimar o volume para diferentes locais, dispensando necessidade de estratificação.
\end{abstract}

Palavras-chave: mogno africano; redes neurais; volumetria.

\section{Use of regression and artificial neural networks in the Khaya ivorensis volume estimate}

\begin{abstract}
This work aimed to compare the volume of African mahogany trees estimated by the Schumacher and Hall model and artificial neural networks (ANNs). Data collection took place in two agroforestry systems in the municipality of Belterra, Pará, Brazil, with 7 and 11 years of age. At each site 34 standing trees were planted. For commercial volume estimates, the forms of the Schumacher and Hall model (linear and nonlinear) and the use of artificial neural networks (RNA) of the Multilayers perceptron type were used. The ANNs architectures with 4 neurons in the input layer provided the best estimates and error values, which are appreciably better than the volumetric models, with RNA being 36.7\% smaller than the non-linear Schumacher and Hall model. The latter model tended to overestimate volumes and RNA obtained more trend-free estimates. Artificial neural networks generated estimates more accurately than the regression model. This technique proved to be feasible, since a single network can estimate the volume for different locations, avoiding the need for stratification.
\end{abstract}

Keywords: African mahogany; neural networks; volumetry. 


\section{Introdução}

O mogno africano (Khaya ivorensis A. Chev.), da família Meliaceae, é uma espécie nativa das regiões de florestas tropicais úmidas da África Ocidental (PINHEIRO et al., 2011). Tal espécie tem sido introduzida no Brasil, principalmente como componente arbóreo de sistemas agroflorestais (SAFs), graças ao seu rápido ritmo de crescimento e ao elevado valor econômico de sua madeira, altamente apreciada no mercado interno e externo (RIBEIRO et al., 2017).

Considerando a importância da espécie e tendo em vista a necessidade do suprimento de madeiras para abastecer o mercado, a quantificação do estoque e do crescimento de povoamentos florestais torna-se fundamental, pois fornece informações quantitativas e qualitativas, auxiliando a avaliação técnica e econômica dos plantios (CORDEIRO et al., 2015). Uma etapa importante para tal avaliação é o procedimento de cubagem de toras para a obtenção do volume de madeira, a qual é onerosa e demorada, sendo necessário aliar métodos indiretos para a sua estimativa, como por exemplo a utilização de modelos volumétricos que representam matematicamente o volume através de equações (SCHRÖDER et al., 2013).

Dentre os modelos para estimativa de volume, o modelo de Schumacher e Hall é o mais conhecido e difundido no meio florestal, sendo largamente empregado para expressar o volume de madeira em função do diâmetro a altura de 1,3 m do solo (Dap) e da altura, graças às suas propriedades estatísticas, que quase sempre geram estimativas com pouca tendenciosidade (CAMPOS; LEITE, 2017). Para facilitar o ajuste e corrigir problemas estatísticos relacionados a pressuposições básicas da regressão, o modelo de Schumacher e Hall normalmente é ajustado na sua forma linear por logaritmo neperiano (SOARES et al., 2011). No entanto, o ajuste de modelos volumétricos é altamente dependente de variáveis categóricas como local, clone, espaçamento e outros, sendo que estas, comumente apresentam relações de não linearidade, tornando a introdução destas variáveis uma tarefa complexa (BINOTI et al., 2014a). Além disso, os modelos de regressão necessitam de suposições sobre as relações entre as variáveis utilizadas no ajuste (BINOTI et al., 2014b).

Sendo assim, aliar novas técnicas que propiciem estimativas mais precisas e contornem as limitações dos métodos tradicionais se faz necessário. Uma alternativa viável são as redes neurais artificiais (RNA), que consistem em uma ferramenta de inteligência computacional que se assemelha à estrutura do cérebro humano, organizado em redes neurais biológicas (CAMPOS et al., 2016). Os neurônios artificiais que formam estas redes calculam funções matemáticas, geralmente não lineares, e são capazes de armazenar informações com intuito de responder apropriadamente ao ambiente, bem como, compilam propriedades de tolerância a ruídos (outliers), introdução de variáveis categóricas, processos de aprendizagem e generalização global (HAYKIN, 2002). Tais características permitem, em alguns casos, um desempenho superior em comparação aos modelos convencionais de regressão (BRAGA et al., 2007).

No Brasil, a utilização das redes neurais artificiais como ferramenta no meio florestal tem sido aplicada em diversos estudos buscando difundir a técnica. Destacam-se os estudos para estimativa de volume individual de árvores (RODRIGUES et al., 2010; GORGENS et al., 2014), de altura (BINOTI et al., 2013a; VENDRUSCOLO et al., 2015), de diâmetro e forma de árvores (LEITE et al., 2011; MARTINS et al., 2016), além de estudos que quantificam os ganhos econômicos a partir da adoção das RNA para estimativas dendrométricas (BINOTI et al., 2013b).

As diferentes técnicas utilizadas para estimar o volume de árvores caracterizam-se como um instrumento importante 
no planejamento da utilização dos recursos florestais. No entanto, ainda são incipientes as pesquisas aplicadas a diferentes modelos produtivos, como os SAFs.

Considerando o exposto, este trabalho objetivou comparar o volume de árvores de mogno africano estimado pelo modelo de Schumacher e Hall e por redes neurais artificiais.

\section{Materiais e Métodos}

\section{Área de estudo}

O presente trabalho foi desenvolvido em dois sistemas agroflorestais no município de Belterra, Pará (Figura 1) situado no Oeste do estado. Segundo classificação de Köppen o clima da região é do tipo Am, com precipitação média de aproximadamente $1743 \mathrm{~mm}$ e temperatura anual média de $25^{\circ} \mathrm{C}$. O solo é predominantemente formado por Latossolo Amarelo de textura argilosa (ESPIRITO-SANTO et al., 2005).

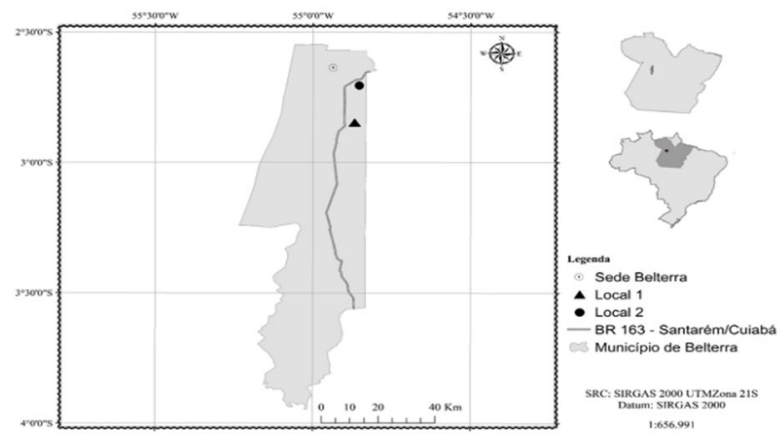

Figura 1. Mapa de localização das áreas de estudo.

Figure 1. Map of the study areas.

O local 1 consiste em um sistema de integração lavourapecuária-floresta (ILPF), com 7 anos de idade e espaçamento de 7 x 5 m entre as árvores de mogno africano, com cultivo de espécies agrícolas nos primeiros dois anos e introdução eventual de bovinos ou equinos durante o ano. As árvores estão distribuídas em 8 linhas de plantio. O local 2 é classificado como um sistema silvipastoril, devido à presença de espécies forrageiras e bovinos. A idade do povoamento é de 11 anos, com espaçamento de $10 \times 10 \mathrm{~m}$ e árvores agrupadas em um renque único, composto por duas filas de plantio.

\section{Coleta de dados}

Foram cubadas 34 árvores em pé de cada local, utilizando o dendrômetro Criterion RD 1000. Aferiu-se o diâmetro nas seções de 0,1, 0,5, 1 e 1,30 m e a partir da altura de 2,0 m, prosseguiu-se a cubagem de metro em metro até bifurcação do fuste, onde considerou-se como altura comercial (Hc). O volume do fuste foi obtido através do método de Smalian. As médias e desvios das variáveis dendrométricas coletadas por local estudado estão na Tabela 1.

Tabela 1. Média e desvio padrão das variáveis dendrométricas de Mogno africano (Khaya ivorensis A. Chev.) em dois sistemas agroflorestais no município de Belterra, PA.

Table 1. Mean and standard deviation of dendrometric variables of African mahogany (Khaya ivorensis A. Chev.) in two agroforestry systems in the municipality of Belterra, PA. $\mathrm{N}=$ Número de árvores; Dap = Diâmetro a altura de $1,3 \mathrm{~m}$ $(\mathrm{cm}) ; \mathrm{Hc}=$ Altura comercial $(\mathrm{m}) ; \mathrm{Ht}=\operatorname{Altura}$ total $(\mathrm{m}) ; \mathrm{V}=$ Volume comercial com casca $\left(\mathrm{m}^{3}\right)$.

\begin{tabular}{cccccc}
\hline Local & $N$ & Dap & $H c$ & $H t$ & $V$ \\
\hline \multirow{2}{*}{1} & \multirow{2}{*}{34} & $24,9 \pm$ & $10,69 \pm$ & $16,86 \pm$ & $0,4843 \pm$ \\
& & 2,8 & 2,89 & 2,54 & 0,1532 \\
\hline \multirow{2}{*}{2} & \multirow{2}{*}{34} & $25,39 \pm$ & $8,96 \pm$ & $15,59 \pm$ & $0,4029 \pm$ \\
& & 3,41 & 2,68 & 2,51 & 0,1598 \\
\hline
\end{tabular}

\section{Processamento de dados}

\section{Ajuste dos modelos}

Foram ajustadas duas formas do modelo de Schumacher e Hall para estimativa de volume, a forma original do modelo (Modelo 1) e a forma linearizada (Modelo 2).

$$
\begin{gathered}
V=\beta 0 * \operatorname{DapHc}^{\beta 2}+\varepsilon \quad(\text { Modelo } 1) \\
\ln V=\beta 0+\ln \operatorname{Dap} \beta 1+\ln H c \beta 2+\varepsilon(\text { Modelo } 2)
\end{gathered}
$$

Em que: $\mathrm{V}=$ volume comercial com casca, em $\mathrm{m}^{3}$; Dap = diâmetro a altura de $1,30 \mathrm{~m}$ do solo, em $\mathrm{cm} ; \mathrm{Hc}=$ altura comercial, em $\mathrm{m} ; \bullet 0, \cdot 1 \mathrm{e} \cdot 2=$ coeficientes; $\ln =$ logaritmo neperiano; $\varepsilon=$ erro aleatório. 
Os modelos foram ajustados por local, por meio do método de estimativa de mínimos quadrados, utilizando o algoritmo Gauss-Newton para a forma não-linear. Para a escolha do melhor modelo, foi utilizado o coeficiente de determinação ajustado ( $\left.\mathrm{R}^{2} \mathrm{aj}\right)$, erro padrão residual (Sy.x\%) e a análise gráfica dos resíduos percentual.

\section{Treinamento das redes neurais artificiais}

Utilizou-se para as estimativas de volume RNA do tipo Multilayer Perceptron (MLP), cujo funcionamento baseia-se na existência de uma ou mais camadas intermediárias de neurônios ocultos, extraindo assim estatísticas de maior performance. As arquiteturas utilizadas são mostradas na Figura 2.

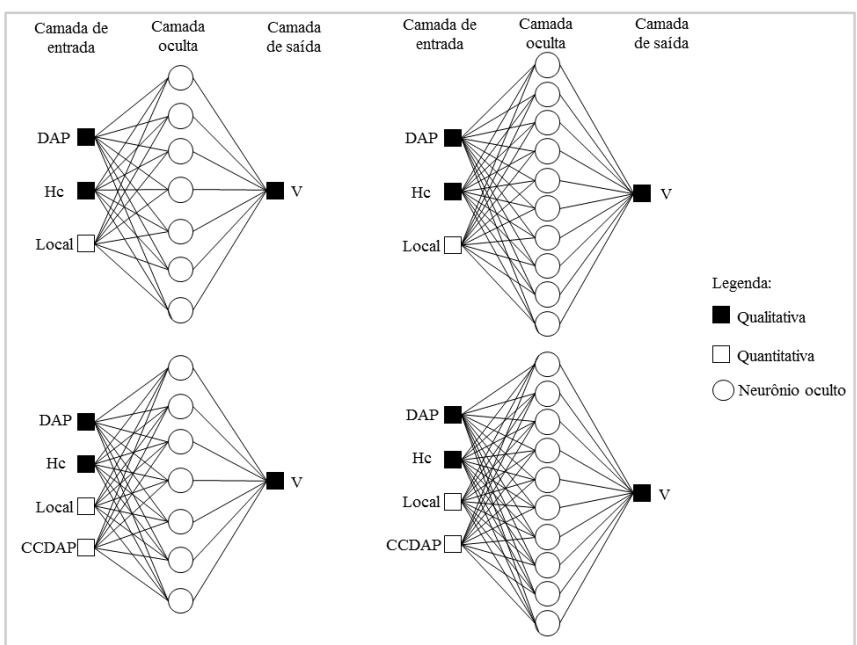

Figura 2. Arquiteturas das redes neurais artificiais utilizadas para estimar o volume comercial com casca de Mogno africano (Khaya ivorensis A. Chev.) em dois sistemas agroflorestais no município de Belterra, PA.

Figure 2. Artificial neural network architectures used to estimate commercial volume with African Mahogany bark (Khaya ivorensis A. Chev.) In two agroforestry systems in the municipality of Belterra, PA.

Testaram-se duas quantidades de neurônios na camada oculta das redes (7 e 10), pois segundo Silva et al. (2009), a determinação do número de neurônios contidos nesta camada oculta é um dos grandes desafios dos usuários das RNA, sendo necessário testar diversas possibilidades buscando encontrar uma arquitetura que responda adequadamente ao fenômeno.

Para a camada de entrada, utilizou-se redes com três e quatro neurônios, sendo que a variável local e a variável centro de classe diamétrica (CCDAP) foram consideradas como variáveis categóricas. Para definição da variável CCDAP, os indivíduos foram agrupados em 4 classes diamétricas, com intervalo de $5 \mathrm{~cm}(17,5 ; 23 ; 28$ e $33 \mathrm{~cm})$.

Os sinais de entrada e saída foram limitados através de função de ativação do tipo sigmoidal, visto que este tipo representa bem relações de não linearidade e o algoritmo de treinamento das redes foi o Resilient Propagation (RPROP+), devido sua ampla utilização e eficácia no ajuste dos pesos sinápticos (HAYKIN, 2002). Foram treinadas para cada arquitetura 150 redes, das quais, selecionou-se as de menor erro, representado pelo bias, de cada arquitetura. O critério de parada para término do treinamento das redes foi o erro médio de 0,0001 ou 3000 ciclos. O treinamento das redes foi feito com o software Neuro $4^{\circledast}$ (BINOTI, 2012).

\section{Comparação dos métodos}

Para definir qual a melhor técnica para a estimativa de volume dos indivíduos cubados em questão, utilizou-se além dos parâmetros tradicionalmente recomendados (coeficiente de correlação entre valores observados e estimados - r e raiz quadrada do erro médio - RQEM\%), as estatísticas adicionais de precisão (Tabela 2), conforme a metodologia indicada por Schikowski et al. (2015). O uso de tais estatísticas permite uma avaliação mais eficiente da precisão das estimativas geradas.

Além da análise das estatísticas de desempenho, os volumes observados e estimados pelos modelos e RNA também foram comparados através do teste F de Graybill a 5\% de significância: 


$$
F\left(H_{0}\right)=\left[\left(C^{\prime} \hat{\beta}-\theta\right)\left(y_{1}{ }^{\prime} y_{1}\right)^{-1}\left(C^{\prime} \hat{\beta}-\theta\right)\right] / 2 Q \text { Mres }
$$

Em que: $\mathrm{C}$ é a matriz identidade de ordem $2 ; \hat{\beta}^{\prime}=\left[\hat{\beta}_{0} \hat{\beta}_{1}\right]$; $\theta^{\prime}=\left[\begin{array}{ll}0 & 1\end{array}\right]$; QMres é o quadrado médio do resíduo e $y_{1}$ é o vetor da variável independente (volume comercial estimado) do modelo $Y_{J}=\beta_{0}+\beta_{1} Y_{1}+\varepsilon, \bullet \sim \operatorname{NID}\left(0, \bullet^{2}\right)$ e $y_{j}$ é o volume comercial observado. A hipótese testada é $\mathrm{H}_{0}: C^{\prime} \beta=\theta$ versus $\mathrm{H}_{\mathrm{a}}$ : Não $\mathrm{H}_{0}$. Dessa forma a não rejeição de $\mathrm{H}_{0}\left(\mathrm{~F}\left(\mathrm{H}_{0}\right)<\mathrm{F}\right.$. (2,n-2)) implica que os valores estimados e observados são estatisticamente coincidentes.

$\mathrm{O}$ erro médio $\left(\bar{e}=\sum_{i=1}^{n}\left[\left(y_{J i}-y_{1 i}\right) / y_{1 i}\right] / \mathrm{n}\right)$ das estimativas foi submetido a um teste $t$, sob condições de normalidade, com estatística do teste dada por:

$$
\begin{gathered}
t_{\bar{e}}=\frac{\bar{e}-0}{S_{\bar{e}}} \\
S_{\bar{e}}=S_{e} / \sqrt{n}, \text { com n-1 g.l. }
\end{gathered}
$$

Testou-se a hipótese $\mathrm{H}_{0}: \bar{e}=0$ e $\mathrm{H}_{\mathrm{a}}$ : não $\mathrm{H}_{0}$. Se $t_{\bar{e}} \cdot t_{\alpha}$ (n1 g.l.) a hipótese $\mathrm{H}_{0}$ não é rejeitada, logo os volumes comerciais observados e estimados são estatisticamente iguais.

Tabela 2. Estatísticas de avaliação da precisão nas estimativas do volume comercial com casca do fuste de Mogno africano (Khaya ivorensis A. Chev.), em dois sistemas agroflorestais no município de Belterra, PA.

Table 2. Precision evaluation statistics on commercial volume estimates with African Mahogany (Khaya ivorensis A. Chev.) bark, in two agroforestry systems in the municipality of Belterra, PA.

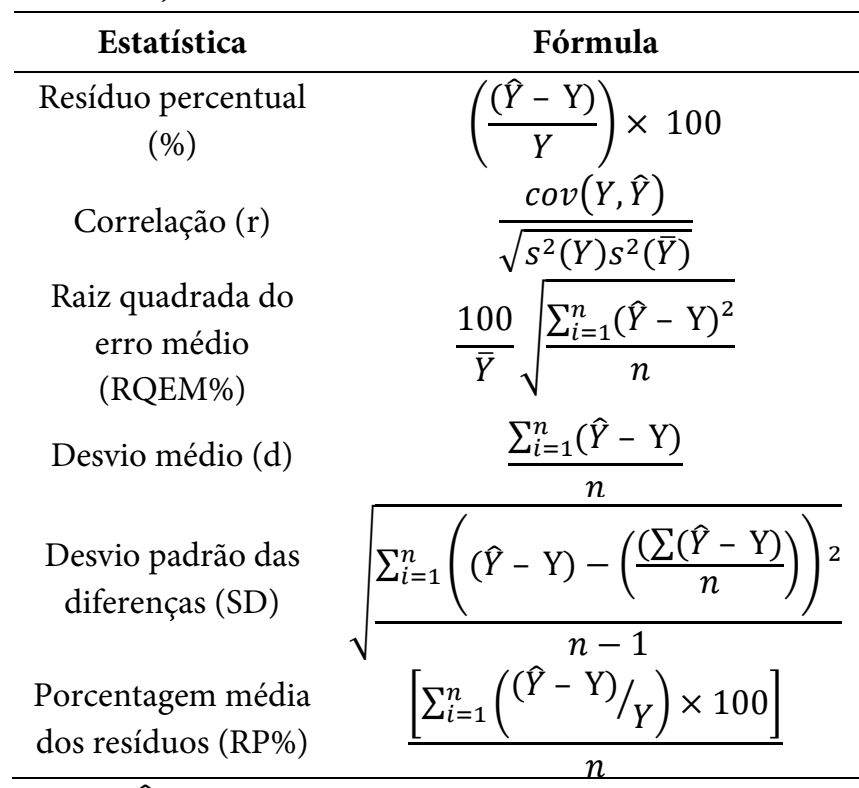

Em que: $\hat{Y}=$ volume comercial com casca estimado da i-ésima árvore, $\mathrm{em} \mathrm{m}^{3} ; Y==$ volume comercial com casca observado da i-ésima árvore, em m³ $; \mathrm{n}=$ número total de observações; $\bar{Y}$ $=$ média do volume comercial com casca observado, $\mathrm{em} \mathrm{m}^{3}$; $\mathrm{s}^{2}=$ desvio padrão.

A partir da avaliação das estatísticas adicionais, procedeuse com a análise gráfica dos resíduos percentuais em relação ao Dap e do histograma de frequência de resíduos, da melhor forma do modelo de Schumacher e Hall e das melhores arquiteturas de RNA, para identificar possíveis tendências nas estimativas de ambas as técnicas.

\section{Resultados e Discussão}

Os resultados dos ajustes dos modelos volumétricos para ambos os locais bem como estatísticas de qualidade dos ajustes estão na Tabela 3.

Tabela 3. Resultado de ajuste das formas do modelo de Schumacher e Hall para as áreas de pesquisa.

\begin{tabular}{|c|c|c|c|c|c|c|}
\hline Local & Modelo & $\bullet_{0}$ & $\bullet_{1}$ & $\cdot 2$ & $\begin{array}{c}S y \cdot x \\
\%\end{array}$ & $R^{2}$ aj \\
\hline \multirow{2}{*}{$\begin{array}{c}\text { Local } \\
1\end{array}$} & $\begin{array}{l}\text { chumacher } \\
\text { e Hall }\end{array}$ & $\begin{array}{c}0,0002 \\
*\end{array}$ & $\begin{array}{c}1,8550 \\
*\end{array}$ & $\begin{array}{c}0,8244 \\
*\end{array}$ & 8,15 & 0,93 \\
\hline & $\begin{array}{l}\text { Schum } \\
\text { e Hall } 1\end{array}$ & $\begin{array}{c}- \\
8,7776 \\
*\end{array}$ & $\begin{array}{c}1,9139 \\
*\end{array}$ & $\begin{array}{l}0,7979 \\
*\end{array}$ & 8,23 & 0,93 \\
\hline \multirow{2}{*}{$\begin{array}{c}\text { Local } \\
2\end{array}$} & $\begin{array}{c}\text { chumacher } \\
\text { e Hall }\end{array}$ & $\begin{array}{c}0,0001 \\
*\end{array}$ & $\begin{array}{l}0035 \\
*\end{array}$ & $\begin{array}{c}0,8209 \\
*\end{array}$ & 7,37 & 0,97 \\
\hline & $\begin{array}{l}\text { Schumacher } \\
\text { e Hall linear }\end{array}$ & $\begin{array}{c}- \\
9,5022 \\
*\end{array}$ & $\begin{array}{c}2,0687 \\
*\end{array}$ & $\begin{array}{l}0,8551 \\
*\end{array}$ & 7,49 & 0,97 \\
\hline
\end{tabular}

Table 3. Results of adjustment of the forms of the Schumacher and Hall model for the research areas.

$\bullet_{0}, \bullet_{1}, \bullet_{2}=$ coeficientes do modelo; $S y . x \%=$ erro padrão da estimativa em porcentagem; $\mathrm{R}^{2} \mathrm{aj}=$ coeficiente $\mathrm{de}$ determinação ajustado $e^{*}=$ significância a 5\%.

Todos os coeficientes foram significativos $(p<0,05)$. O modelo de Schumacher e Hall na sua forma não linear apresentou estatísticas de ajuste sensivelmente melhores quando comparadas ao modelo linear, com erro padrão residual de $7,37 \%$ e $8,15 \%$, para os locais 1 e 2 respectivamente. 
O modelo de Schumacher e Hall na sua forma não linearizada geralmente apresenta boa precisão no ajuste de estimativas volumétricas, apesar de pouco utilizada devido à complexidade de seu ajuste em detrimento a forma linear. Ao testar a aplicação da forma não linear, Binoti et al. (2014b) encontram resultados satisfatórios para o desempenho e aplicação deste modelo para predição do volume de Eucalyptus sp.

A comparação destas equações com as RNA foi realizada com as estatísticas de precisão (Tabela 4).

Todas as técnicas utilizadas obtiveram valores satisfatórios para os estimadores estatísticos avaliados e apresentaram volumes estimados estatisticamente iguais aos observados, segundo os testes F e t com 5\% de significância (Tabela 4). No entanto, pode-se observar que as RNA proporcionaram valores de RQEM\% menores aos ajustes dos modelos volumétricos, tendo as RNA 4-10-1, denotando um erro $36,7 \%$ menor do que o modelo de Schumacher e Hall na sua forma não linear, cujo erro foi o menor entre os modelos ajustados. No que se refere ao desvio padrão das diferenças (SD), observa-se que os modelos de regressão apresentaram valores superiores aos das RNA, o que indica menor homogeneidade entre os resíduos nas estimativas por regressão.

Os valores de desvio médio (d) foram próximos a zero, inferindo que não há fortes tendências nas estimativas geradas pelos dois métodos. Dentre as arquiteturas de redes neurais, as que obtiveram melhores resultados foram as com 4 neurônios contidos na camada de entrada, com RQEM\% entre 4,76\% e 5,73\%, e coeficientes de correlação de 0,99.

A introdução da variável categórica CCDAP resultou em ganhos em precisão das estimativas, visto que as arquiteturas 4-7-1 e 4-10-1 obtiveram as melhores performances de treinamento, segundo as estatísticas de desempenho. Destaca-se que a RNA 4-7-1 resultou nos maiores $p$-valores para ambos os testes, indicando maior precisão ao estimar o volume comercial de Mogno africano.

A implementação do centro de classe diamétrica em arquiteturas de redes neurais artificiais para estimativas de volume não é relatada na literatura, mesmo se tratando de uma variável secundária de fácil obtenção que pode gerar ganhos em precisão, como demonstrado neste estudo.

Tabela 4. Estatísticas de precisão das formas ajustadas do modelo de Schumacher e Hall e RNA treinadas para a estimativa do volume comercial com casca de Mogno africano (Khaya ivorensis A. Chev.) em dois sistemas agroflorestais no município de Belterra, PA.

Table 4. Precision statistics of the adjusted forms of the Schumacher and Hall model and trained RNA for estimating the commercial volume with African Mahogany (Khaya ivorensis A. Chev.) bark in two agroforestry systems in the municipality of Belterra, PA.

\begin{tabular}{cccccccc}
\hline Método & $\mathrm{r}$ & $\mathrm{d}$ & $\mathrm{SD}$ & $\mathrm{RP} \%$ & $\mathrm{RQEM} \%$ & p-valor $\mathrm{F}\left(\mathrm{H}_{0}\right)$ & $p$-valor t $\bar{e}$ \\
\hline Schumacher e Hall não linear & 0,98 & $2 \mathrm{E}-04$ & 0,2751 & 0,86 & 7,52 & 0,1676 & 0,3775 \\
Schumacher e Hall linear & 0,98 & $-1 \mathrm{E}-03$ & 0,2783 & 0,29 & 7,61 & 0,3626 & 0,7598 \\
RNA 3-7-1 & 0,99 & $-4 \mathrm{E}-05$ & 0,2229 & 0,49 & 6,09 & 0,3350 & 0,5602 \\
RNA 3-10-1 & 0,99 & $-9 \mathrm{E}-05$ & 0,2113 & 0,37 & 5,78 & 0,3235 & 0,6227 \\
RNA 4-7-1 & 0,99 & $-4 \mathrm{E}-04$ & 0,2094 & 0,11 & 5,73 & 0,5463 & 0,8832 \\
RNA 4-10-1 & 0,99 & $-2 \mathrm{E}-04$ & 0,1743 & 0,24 & 4,76 & 0,4642 & 0,7149 \\
\hline
\end{tabular}

$\mathrm{r}=$ coeficiente de correlação entre volume comercial com casca observado e estimado; $\mathrm{d}=$ desvio médio; $\mathrm{SD}=\mathrm{Desvio}$ padrão das diferenças; $\mathrm{RP} \%$ = Porcentagem média dos resíduos; RQEM\% = Raiz quadrada do erro médio em porcentagem; $\mathrm{F}(\mathrm{H} 0)=$ Teste $\mathrm{F}$ de Graybill e t $\bar{e}=$ Teste $\mathrm{t}$ para o erro médio. 
Uma das principais vantagens da utilização das RNA reside na possibilidade da inserção de variáveis categóricas, como local e CCDAP, eliminando a necessidade de estratificação dos dados para cada compartimento, como na regressão tradicional, refletindo em ganhos na precisão das estimativas e na diminuição de amostragem (HAYKIN, 2002; CAMPOS et al., 2016).

Além disso, durante a fase de treinamento as RNA buscam relacionar os padrões encontrados dentro de todo o conjunto de dados com a variável a ser estimada, não se limitando a subconjuntos de variáveis preditoras (GORGENS et al., 2015). A classificação das árvores, a partir do CCDAP, cria um novo padrão dentro da amostra, gerando estimativas volumétricas mais concisas.

Dentre os gráficos de dispersão dos resíduos percentuais (Figura 3), o modelo de Schumacher e Hall, nas duas formas, apresentou maior dispersão na distribuição dos resíduos, principalmente para árvores com Dap menor que $25 \mathrm{~cm}$. No geral as RNA demonstraram menor amplitude entre os valores estimados e observados, no entanto, as RNA com três neurônios na camada de entrada proporcionaram tendência a superestimar os volumes. Os resíduos da RNA com quatro neurônios na camada de entrada têm uma distribuição mais próxima da reta de regressão e pouca tendência nas estimativas, demonstrando novamente a superioridade das arquiteturas com a variável CCDAP.

A Figura 4 contém a análise gráfica da dispersão dos resíduos percentuais e do histograma de frequência. Quanto à frequência dos resíduos, $41 \%$ esteve concentrada entre - $2 \%$ e $2 \%$. O modelo de Schumacher e Hall, nas duas formas, apresentou tendência a superestimar os volumes, com $40 \%$ dos resíduos dispersos em classes $>2 \%$. As RNA com quatro neurônios na camada de entrada obtiveram 56\% dos resíduos nas classes de $-2 \%$ a $2 \%$, sendo o método mais livre de tendências de estimativa.
De forma geral, as estimativas geradas pelas redes neurais artificiais se mostraram superiores às tradicionais formas do modelo de Schumacher e Hall, tanto nas estatísticas de precisão, quanto na avaliação gráfica dos erros.

A superioridade dessa técnica, em relação ao modelo de Schumacher e Hall, também foi constatada por Silva et al. (2009) com uso das RNA, demonstrando boa eficácia para a estimativa de volume de Eucalipto. Ao comparar a forma não linear de Schumacher e Hall e o uso de RNA, Cordeiro et al. (2015) também identificaram superioridade das redes para a volumetria de Acacia mangium.

Um fator determinante no desempenho das redes neurais em relação aos modelos de regressão, é a sua capacidade de detectar a existência de relações não-lineares complexas entre as variáveis de entrada e saída, tal característica é útil na modelagem do volume de árvores (ÖZÇELIK et al., 2010).

Observando os ajustes por local de estudo, as variações de estimativas tiveram o mesmo comportamento geral, e as RNA 4-7-1 e 4-10-1 foram capazes de distinguir melhor, as diferentes idades e prováveis variações de sítio. De acordo com Gorgens et al. (2009), esse fato se deve a possibilidade de introdução de variáveis categóricas e da capacidade de generalização e conectividade intrínsecas às redes.

\section{Conclusões}

Tanto o modelo de regressão de Schumacher e Hall como as redes neurais artificiais estimam com exatidão o volume das árvores de mogno africano em sistema agroflorestal, sendo esta exatidão um pouco maior com o emprego de uma RNA multilayer perceptron, com 7 neurônios na camada oculta, função sigmoidal nas camadas de entrada e saída, treinada pelo algoritmo resiliente propagation, utilizando com variáveis de entrada o Dap, altura comercial, locais e a classe diamétrica. O emprego da RNA dispensa a necessidade de estratificação por local e permite o uso de uma menor quantidade de dados de árvores-amostra. 


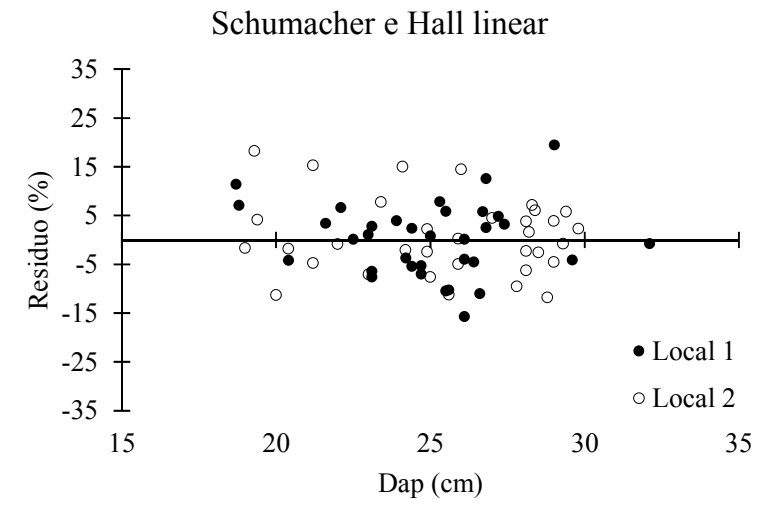

RNA 3-7-1

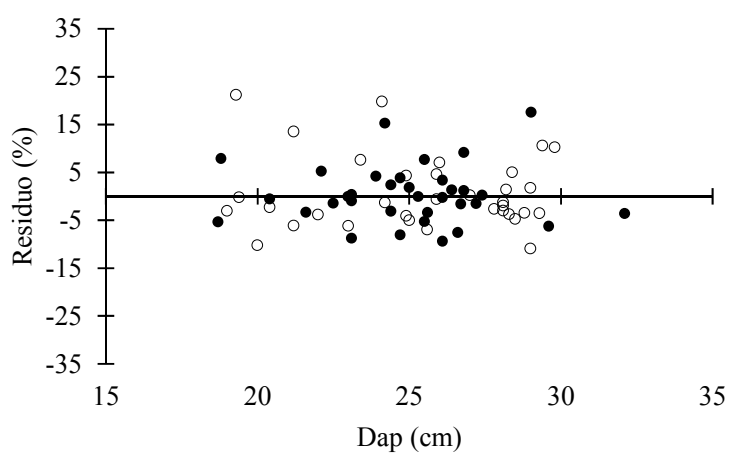

RNA 4-7-1

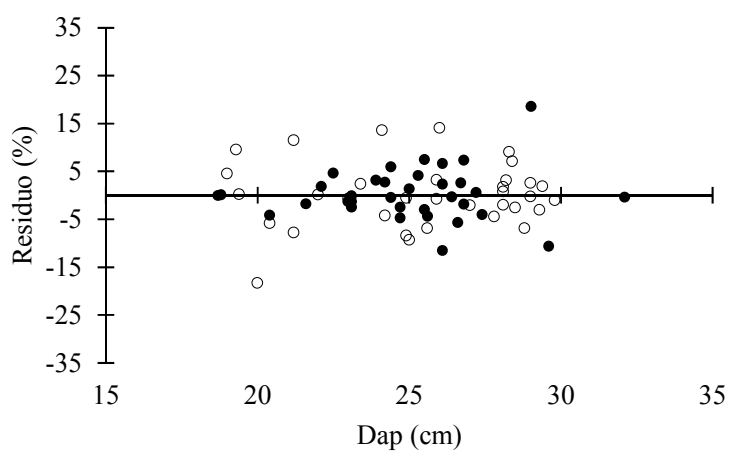

Schumacher e Hall não linear

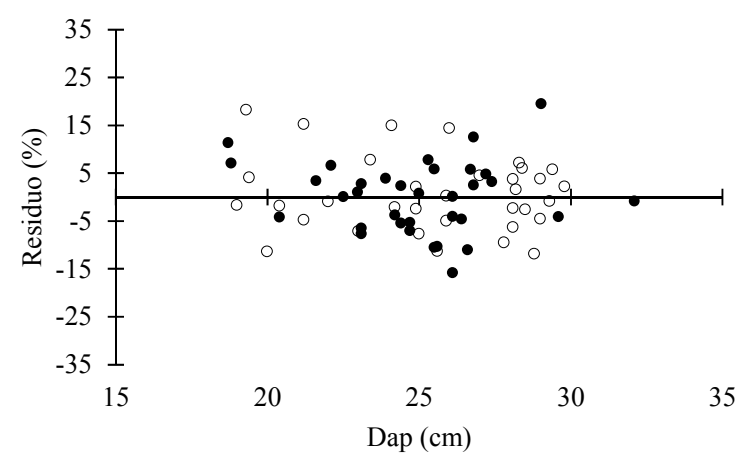

RNA 3-10-1

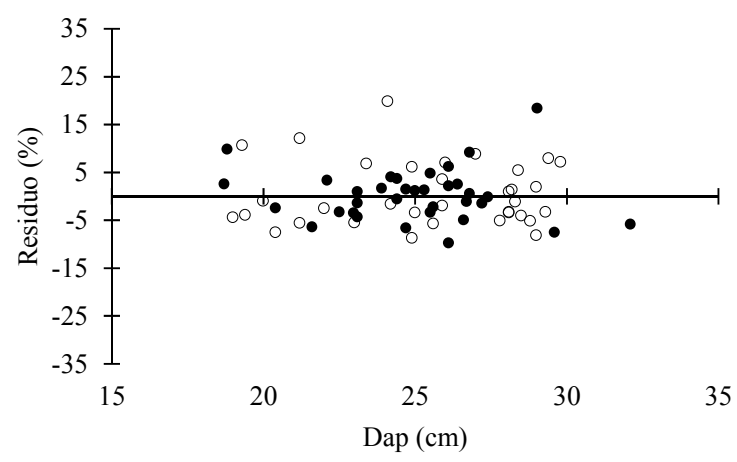

RNA 4-10-1

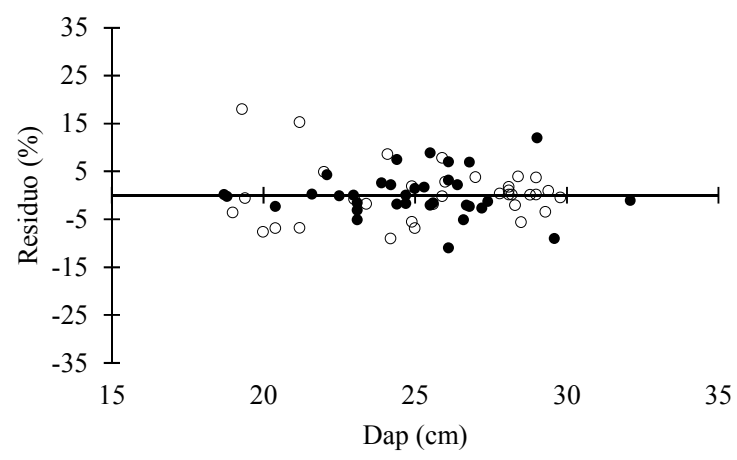

Figura 3. Dispersão gráfica dos resíduos percentuais do volume comercial por Dap $(\mathrm{cm})$ para Mogno africano (Khaya ivorensis A. Chev.) em dois sistemas agroflorestais no município de Belterra, PA.

Figure 3. Graphical dispersion of residues percentage of commercial volume per Dbh (cm) for African mahogany (Khaya ivorensis A. Chev.) in two agroforestry systems in the municipality of Belterra, PA. 

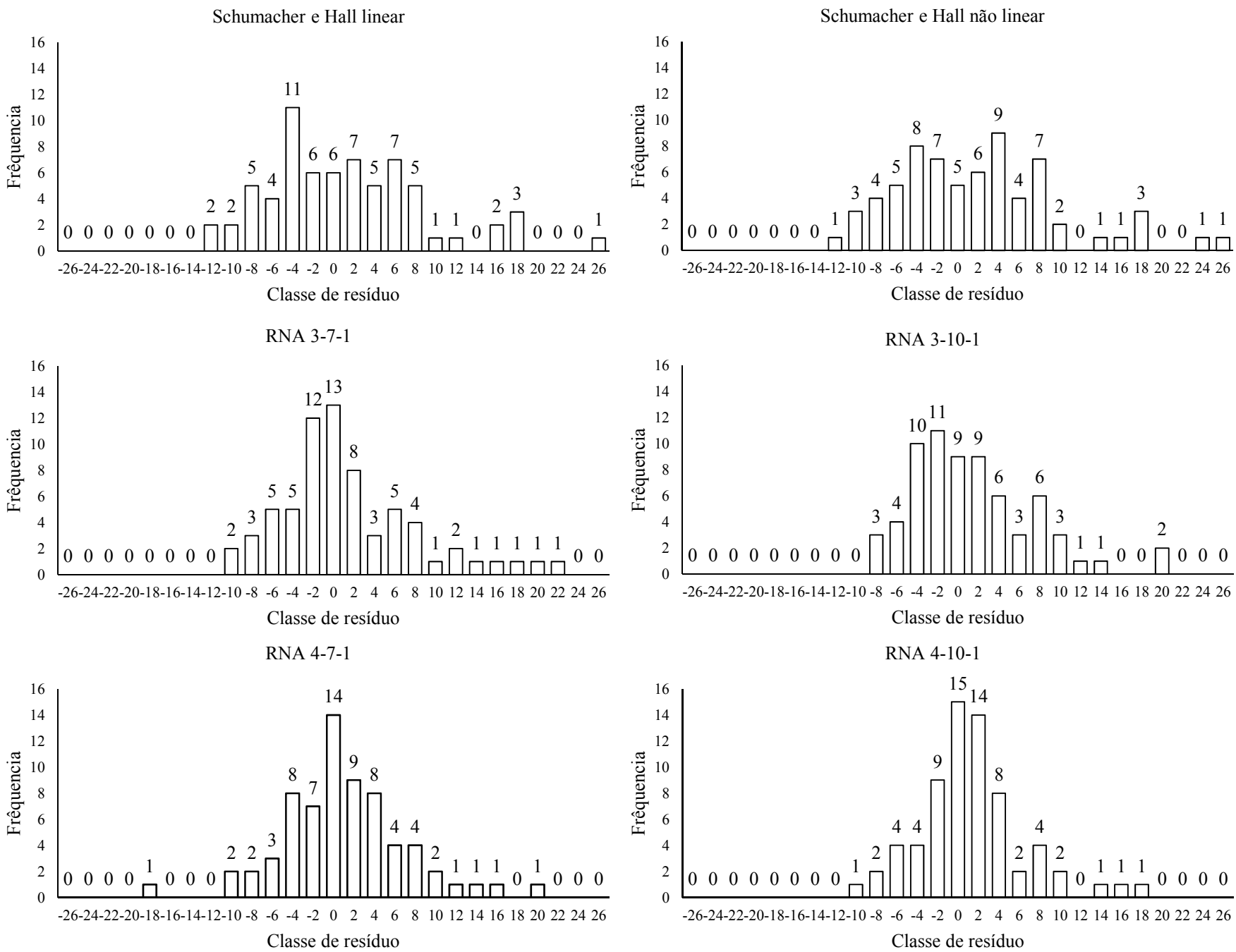

Figura 4. Histograma de frequência de resíduos percentuais das estimativas de volume comercial para Mogno africano (Khaya ivorensis A. Chev.) em dois sistemas agroflorestais no município de Belterra, PA.

Figure 4. Histogram of percentage residuals of commercial volume estimates for African mahogany (Khaya ivorensis A. Chev.) in two agroforestry systems in the municipality of Belterra, PA.

\section{Agradecimentos}

Ao Conselho Nacional de Desenvolvimento Científico e Tecnológico pela concessão da bolsa de pós-graduação ao primeiro autor.

Ao Sr. Roberto Massafra, proprietário da Fazenda Boa Safra e ao Sr. Minoli, proprietário da Fazenda Nossa Sra. Aparecida, por permitirem a coleta de dados em suas propriedades.

\section{Referências}

BINOTI, M. L. S. Emprego de redes neurais artificiais em mensuração e manejo florestal. 2012. Tese (Doutorado em Ciências Florestais) - Universidade Federal de Viçosa, 2012.

BINOTI, D. H. B.; BINOTI, M. L. S.; LEITE, H. G.; SILVA, A. Redução dos custos em inventário de povoamentos equiâneos. Agrária: Revista Brasileira de Ciências Agrárias, v.8, n.1, p.125-129, 2013b.

BINOTI, M. L. M. S.; BINOTI, D. H. B.; LEITE, H. G. Aplicação de redes neurais artificiais para estimação da altura de povoamentos equiâneos de eucalipto. Revista Árvore, v.37, n.4, p.639-645 2013a. 
BINOTI, D. H. B.; BINOTI, M. L. M. S.; LEITE, H. G. Aplicação de redes neurais artificiais para estimação do volume de árvores. Ciência da Madeira, Pelotas, v.5, n.1, p.58-67, 2014 .

BINOTI, M. L. M. S.; BINOTI, D. H. B; LEITE, H. G.; GARCIA, S. L. R.; FERREIRA, M. Z.; RODE, R.; SILVA, A. A. L. Redes neurais artificiais para estimação do volume de árvores. Revista Árvore, Viçosa, v.38, n.2, p.283-288, 2014 b.

BRAGA, A. P.; CARVAlHO, A. P. L. F.; LUDEMIR, T. B. Redes neurais artificiais: teoria e aplicações. 2. ed. Rio de Janeiro: LTC, 2007. 260p.

CAMPOS, B. P. F.; SILVA, G. F.; BINOTI, D. H. B; MENDONÇA, A. R.; LEITE, H. G. Predição da altura total de árvores em plantios de diferentes espécies por meio de redes neurais artificiais. Pesquisa Florestal Brasileira, Colombo, v.36, n.88, p.375-385, 2016.

CAMPOS, J. C. C.; LEITE, H. G. Mensuração Florestal: perguntas e respostas. 5.ed. Viçosa: Editora UV. 2017. 605p.

CORDEIRO, M. A.; PEREIRA, N. N. J.; BINOTI, D. H. B.; BINOTI, M. L. M. S.; LEITE, H. G. Estimativa do volume de Acacia mangium utilizando técnicas de redes neurais artificiais e máquinas vetor de suporte. Pesquisa Florestal Brasileira, Colombo, v.35, n.83, p.255-261, 2015.

ESPÍRITO-SANTO, F. D. B.; SHIMABUKURO, Y. E.; ARAGÃO, L. E. O. C. de; MACHADO, E. L. M. Análise da composição florística e fitossociológica da Floresta Nacional do Tapajós com o apoio geográfico de imagens de satélites. Revista Acta Amazônica, Manaus, v.35, n.2, p.155-173. 2005.

GORGENS, E. B.; LEITE, H. G.; GLERIANI, J. M.; SOARES, C. P. B.; CEOLIN, A. Estimação do volume de árvores utilizando redes neurais artificiais. Revista Árvore, Viçosa, MG, v.33, n.6, p.1141- 1147, 2009.

GORGENS, E.B.; LEITE, H.G.; GLERIANI, J.M.; SOARES, C.P.B; CEOLIN, A. Influência da arquitetura na estimativa de volume de árvores individuais por meio de redes neurais artificiais. Revista Árvore, v. 38, n.2, p. 289-295, 2014.

GORGENS, E. B.; MONTAGHI, A.; RODRIGUEZ, L. C. E. A performance comparison of machine learning methods to estimate the fast-growing forest plantation yield based on laser scanning metrics. Computers and Electronics in Agriculture, v.116, p. 221-227, 2015.
HAYKIN, S. Redes Neurais: princípios e prática. 2 $2^{\mathrm{a}}$ ed. Porto Alegre: Bookman, 2002. 900p.

LEITE, H.G.; SILVA, M.L.M.; BINOTI, D.H.B.; FARDIN, L.; TAKIZAWA, F.H. Estimation of inside-bark diameter and heartwood diameter for Tectona grandis Linn. trees using artificial neural networks. European Journal of Forest Research, v.130, n.2, p.263-269, 2011.

MARTINS, E. R.; BINOTI, M. L. M. S.; LEITE, H. G.; BINOTI, D. H. B.; GLEYCE DUTRA, G. C. Configuração de redes neurais artificiais para estimação do afilamento do fuste de árvores de eucalipto. Agrária - Revista Brasileira de Ciências Agrárias. v.11, n.1, p. 33-38, 2016.

ÖZÇELIK, R.; DIAMANTOPOULOU, M. J.; BROOKS, J. R.; WIANT JR, H. V. Estimating tree bole volume using artificial neural network models for four species in Turkey. Journal of Environmental Management. v.91, n.3, p.742-753, 2010.

PINHEIRO, A. L.; COUTO, L.; PINHEIRO, D. T.; BRUNETTA, J. M. F. C. Ecologia, silvicultura e tecnologia de utilização dos Mognos-Africanos (Khaya spp.). $1^{\text {a }}$ ed. Viçosa: Sociedade Brasileira de Agrossilvicultura -, MG, 2011. 102p.

RIBEIRO, A.; FERRAZ FILHO, A. C.; SCOLFORO, J. R. S. Cultivo do Mogno Africano (Khaya spp.) e o Crescimento da Atividade no Brasil. Floresta e Ambiente, v.24, e00076814, p.1-11, 2017.

RODRIGUES, F. E.; OLIVEIRA, T. F.; MADRUGA, M. R.; SILVEIRA, A. M. Um método para determinar o volume comercial do Schizolobium amazonicum (Huber) Ducke utilizando redes neurais artificiais. Revista Brasileira de Biometria. São Paulo, v.28, n.1, p.16-23, 2010.

SCHIKOWSKI, A. B.; CORTE, A. N. D.; SANQUETTA, C. R. Estudo da forma do fuste utilizando redes neurais artificiais e funções de afilamento. Pesquisa Florestal Brasileira, Colombo, v.35, n.82, p.119-127, 2015.

SCHRÖDER, T.; HOFIÇO, N. A. S.; ZIMMERMANN, A. P. L.; PEREIRA, L. D.; ROCHA JUNIOR, D. S.; MEYER, E. A.; FLEIG, F. D. Métodos de estimativa de volume comercial para Eucalyptus grandis: especificidades e recomendações. Pesquisa Florestal Brasileira, Colombo, v.33, n.73, p.1-7, 2013.

SILVA, M. L. M.; BINOTI, D. H. B.; GLERIANI, J. M.; LEITE, H. G. Ajuste do modelo de Schumacher e Hall e aplicação de redes neurais artificiais para estimar o volume de árvores de 
eucalipto. Revista Árvore, Viçosa. v.33, n.6, p.1133-1139, 2009.

SOARES, C. P. B.; PAUlA NETO, F.; SOUZA, A. P. Dendrometria e Inventário florestal. 2. Ed. - Viçosa: Editora UFV. 2011. 227p.

VENDRUSCOLO, D. G. S.; DRESCHER, R. SOUZA, H. S.; MOURA, J. P. V. M.; MAMORÉ, F. M. D.; SIQUEIRA, T. A. S. Estimativa da altura de eucalipto por meio de regressão não linear e redes neurais artificiais. Revista Brasileira de Biometria. São Paulo, v. 33, n. 4, p.556-569, 2015. 